\title{
CHEMICAL AND ANTIOXIDANT PROPERTIES OF FUNCTIONAL COMPOUNDS EXTRACTED FROM SIRAITIA GROSVENORII BY SUBCRITICAL WATER
}

\author{
H. Xu, M. Xu, F. Yuan and Y. GaO* \\ Beijing Advanced Innovation Center for Food Nutrition and Human Health, Beijing Laboratory for Food Quality \\ and Safety, Beijing Key Laboratory of Functional Food from Plant Resources, College of Food Science and \\ Nutritional Engineering, China Agricultural University, P. O. Box 112, No.17 Qinghua East Road, Haidian \\ District, 100083, P.R. China
}

(Received: 17 April 2015; accepted: 14 September 2015)

Extracts from lo-han-kuo (Siraitia grosvenorii) are of high sweetness and low calories, and they have been widely used as a natural sweetener to reduce the risk of obesity and diabetes. In the current study, lo-han-kuo extracts were extracted using subcritical water under different operation condition. The study revealed that the optimal extracting parameters were: extraction time of $20 \mathrm{~min}$, extraction temperature of $140{ }^{\circ} \mathrm{C}$, and the addition of $15 \%$ ethanol. Antioxidant activity, contents of total flavonoids, and total phenolic compounds of lo-han-kuo extracts were also investigated. A mathematical model was established to describe the relationship between antioxidant capacity and content of bioactive components in lo-han-kuo extract, and it was found that antioxidant capacity of the extracts was mainly attributed to the yields of total mogrosides $(\mathrm{P}<0.05)$.

Keywords: subcritical water extraction, Siraitia grosvenorii, mogrosides, phenols, antioxidant capacity

Fruit of Siraitia grosvenorii, known as lo-han-kuo, are traditionally used for the treatment of pharyngitis or pharyngeus pain in China. The main functional components are triterpene glycosides (accounting for 3-4\%), and mogroside $\mathrm{V}$ is the most important one. Both mogroside $\mathrm{V}$ and crude lo-han-kuo extracts have been approved as non-nutritive highintensity sweeteners and flavour enhancers (XIA et. al., 2008). The mogrosides presented a strong antioxidant capacity as well (TAKASAKI et al., 2003; Qi et al., 2008; PAN et al., 2009).

Lo-han-kuo extract was obtained mainly by solvent extraction with or without microwave and ultrasound assistance. These methods were time-consuming with low extraction efficiency and not environmental friendly (TEO et al., 2010). Recently, subcritical water has been regarded as an excellent solvent for natural extracts, because subcritical water extraction (SWE) is more economical, efficient, and clean. However, there was little information available on SWE of lo-han-kuo.

The objective of this study was to investigate the influence of SWE parameters on the yield of lo-han-kuo extract and mogroside V. In addition, antioxidant capacity of lo-han-kuo extract was evaluated using 2,2-diphenyl-1-picrylhydrazyl (DPPH) antiradical test. The contents of flavones and phenolic compounds of lo-han-kuo extract were also measured.

\footnotetext{
* To whom correspondence should be addressed.

Phone: +86-10-6273 7034; fax: + 86-10-6273 7986; e-mail: gyxcau@126.com
} 


\section{Materials and methods}

\subsection{Materials and chemicals}

Dried medium size (48-51 mm diameter) of intact Siraitia grosvenorii fruit were grounded to pass a $0.42 \mathrm{~mm}$ sieve (mesh size 40 ) and collected for experiments.

DPPH (2,2-diphenyl-1-picrylhydrazyl), Folin-Ciocalteu reagent (2N), gallic acid, rutin (98\% HPLC), and Trolox (6-hydroxy-2,5,7,8-tetramethylchroman-2-carboxylic acid) were purchased from Sigma-Aldrich Chemical Co. Ltd (Shanghai, China). Mogroside V (95\% purity) was purchased from Shanghai Tongtian Biotechnology Co., Ltd. (Shanghai, China). All the solvents for HPLC analysis were purchased from Merck (Darmstadt, Germany). Other chemicals were purchased from Beijing Chemical Co. (Beijing, China).

\subsection{Subcritical water extraction}

All the subcritical water extraction experiments were carried out following $\mathrm{XU}_{\mathrm{U}}$ and coworkers (2015). Aliquots ( $5 \mathrm{~g}$ ) of raw material were extracted. When the extraction was finished, the extracts were collected, cooled, and centrifuged (4000 r.p.m., $10 \mathrm{~min}$ ), the supernatant was stored at $4{ }^{\circ} \mathrm{C}$ for further use. During extraction, the temperatures were set at 80 to $200{ }^{\circ} \mathrm{C}$, and extraction time was set for 5 to $40 \mathrm{~min}$. The pressure was set at $4 \mathrm{MPa}$ to keep the water in liquid state. The ratio of lo-han-kuo powder to water was 1:30. Different amounts of ethanol (15-55\%) were also added to test its role as a co-solvent used in extraction (XIA et al., 2008; GAO et al., 2010).

\subsection{Total phenolics and flavonoids analysis}

Total phenolics and flavonoids in lo-han-kuo extracts were analysed by colorimetric method (Xu et al., 2015), and the results were expressed as gram of gallic acid equivalents per gram of dry weight. For the analysis of total phenolics in lo-han-kuo SWE extracts, $0.5 \mathrm{ml}$ of the extract dilute was mixed with $2.5 \mathrm{ml}$ of Folin-Ciocalteu's reagent $\left(0.2 \mathrm{~mol} \mathrm{l}^{-1}\right)$. After $5 \mathrm{~min}$, $2.0 \mathrm{ml}$ of sodium carbonate solution $(7.5 \%, \mathrm{w} / \mathrm{v})$ was added and blended. The mixture was incubated for $120 \mathrm{~min}$ at room temperature. The absorbance of the extract was measured at $760 \mathrm{~nm}$ using a spectrophotometer (Shimadzu UV-1800, Tokyo, Japan).

When detecting total flavonoid content, $4 \mathrm{ml}$ of the extract dilute was mixed with $0.3 \mathrm{ml}$ of $\mathrm{NaNO}_{3}(5 \%, \mathrm{w} / \mathrm{v})$. After $5 \mathrm{~min}, 3.0 \mathrm{ml}$ of aluminium chloride $(1 \%, \mathrm{w} / \mathrm{v})$ was added and left for reaction for $6 \mathrm{~min}$, and then $2.0 \mathrm{ml}$ of sodium hydroxide $\left(1 \mathrm{~mol} \mathrm{l}^{-1}\right)$ was added. At last, water was added to the mixture to the volume of $10 \mathrm{ml}$ and blended. Absorbance of mixtures was measured at $510 \mathrm{~nm}$ after $10 \mathrm{~min}$ of reaction.

\subsection{Total mogrosides and mogroside V analysis}

The total mogrosides in lo-han-kuo extracts was quantified by vanillin-sulphuric acid method (ZHANG et al., 2006) and calculated from the calibration curve of mogroside V. Aliquots $(0.5$ $\mathrm{ml})$ of appropriately diluted sample, $10 \%$ vanillin solution in glacial acetic acid $(0.5 \mathrm{ml})$ and $75 \%(\mathrm{v} / \mathrm{v})$ sulphuric acid solution $(5 \mathrm{ml})$ were added into a stoppered test tube and shaken well to obtain a homogeneous solution. Then the mixture was heated in a water bath at $50{ }^{\circ} \mathrm{C}$ for $20 \mathrm{~min}$ and then cooled in a water-ice bath for 2-5 min. The absorbance of the coloured solution was measured at $610 \mathrm{~nm}$. 
The quantification of mogroside V was analysed on a HPLC system (1200 series, Agilent Technologies, Santa Clara, USA) with a Zorbax $\mathrm{NH}_{2}$ column $(250 \mathrm{~mm} \times 4.6 \mathrm{~mm}$ i.d., $5 \mu \mathrm{m})$ via external standard calibration (Lu et al., 2008). The mobile phase was a solution of acetonitrile $(85 \%, \mathrm{v} / \mathrm{v})$ at a flow rate of $1 \mathrm{ml} \mathrm{min}^{-1}$. The injection volume was $5 \mu \mathrm{l}$. Column temperature was $35{ }^{\circ} \mathrm{C}$ and the detection was performed at $210 \mathrm{~nm}$. Mogroside $\mathrm{V}$ was identified by direct comparison of its retention time with that of the authentic compound under identical conditions and by spiking the extract with the reference, and further confirmed by MS analysis.

\subsection{Antioxidative capacities analysis}

DPPH radical scavenging test was carried out following the method described by XU and coworkers (2015) and expressed in Trolox equivalent antioxidant capacity (TEAC). The stock solution of DPPH $\cdot\left(1.75 \times 10^{-4} \mathrm{~mol} \mathrm{l}^{-1}\right)$ was freshly prepared by adding $2 \mathrm{mg}$ DPPH in $50 \mathrm{ml}$ methanol. DPPH solution $(2.0 \mathrm{ml})$ and appropriately diluted sample $(2.0 \mathrm{ml})$ were mixed at ambient temperature (ca. $21^{\circ} \mathrm{C}$ ). The reaction lasted for $60 \mathrm{~min}$ in dark and the absorbance was measured at $517 \mathrm{~nm}$ with a spectrophotometer. The result of the free radical scavenging capacity was expressed in milligram Trolox equivalent per gram of dry weight $\left(\mathrm{mg} \mathrm{g}^{-1}\right)$.

\subsection{Statistical analysis}

One-way analysis of variance (ANOVA) was used to assess statistical differences between extractions.

\section{Results and discussion}

In this study, the lo-han-kuo powder (moisture, $9.80 \pm 0.02 \%$ ) was first defatted by supercritical $\mathrm{CO}_{2}$ at $30.0 \mathrm{MPa}, 55^{\circ} \mathrm{C}$ with a flow rate of $15.0 \mathrm{l} \mathrm{h}^{-1}$ for $2 \mathrm{~h}$. The yield of oil extract was $6.64 \pm 0.05 \%$. The biggest contribution of volatile compounds in the lo-han-kuo essential oil were 2,4-nonadienals based on GC-MS analysis (data not shown).

\subsection{Effect of SWE parameters on the contents of mogrosides and mogroside $V$}

The effect of extraction time on the recovery of mogrosides and mogroside $\mathrm{V}$ were shown in Figure 1A. The recovery of mogrosides got an equilibrium $(\mathrm{P}>0.05)$ over $20 \mathrm{~min}$ and reached a plateau $(70.5 \%)$ in $30 \mathrm{~min}$. The result was consistent with the findings reported by XIA and co-workers (2008). However, the mogroside V content did not follow the same trend as that of mogrosides, and the maximum content of mogroside $\mathrm{V}$ was $17.94 \mathrm{mg} \mathrm{g}^{-1}$ at $10 \mathrm{~min}$. Further decomposition or depredation of mogrosides may occur when the extraction was performed at $140{ }^{\circ} \mathrm{C}$ for more than $20 \mathrm{~min}$. To get the highest mogrosides recovery and mogroside $\mathrm{V}$ content, the recommended extraction time is $20 \mathrm{~min}$. 
A

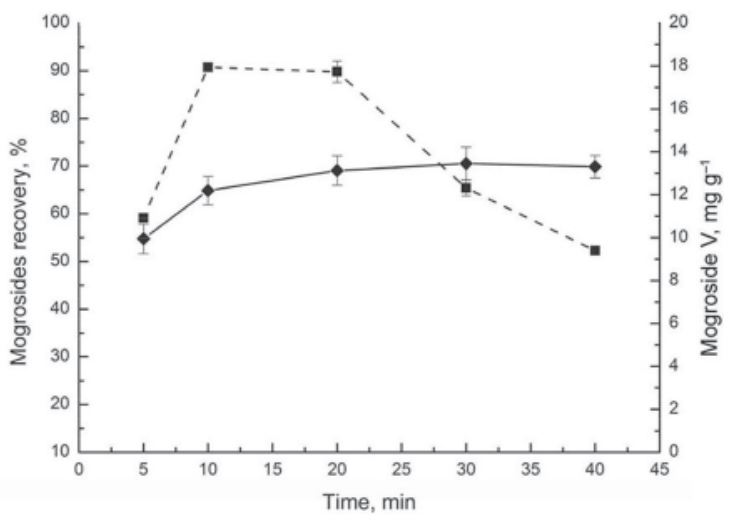

B
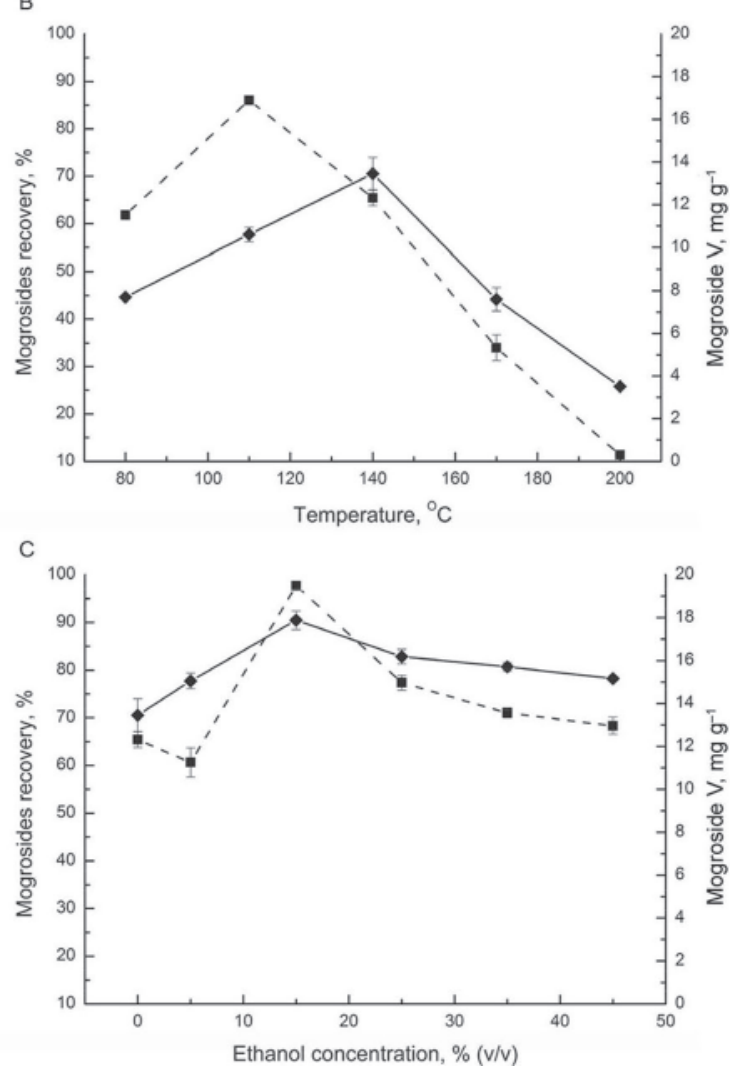

Fig. 1. Effects of subcritical water extraction (SWE) parameters on the recoveries of mogrosides and mogroside $\mathrm{V}$ $(\checkmark$ : mogrosides; $\mathbf{n}$ : mogroside V).

A: The effect of SWE time on the recoveries of mogrosides and mogroside $\mathrm{V}$ (temperature, $140{ }^{\circ} \mathrm{C}$, solid-to-liquid ratio, 1:30, pressure, $4 \mathrm{MPa}$ );

B: The effect of SWE temperature on the recoveries of mogrosides and mogroside V (solid-to-liquid ratio, 1:30, pressure, $4 \mathrm{MPa}$, time, $30 \mathrm{~min}$ );

$\mathrm{C}$ : The effect of ethanol concentration on the recoveries of mogrosides and mogroside $\mathrm{V}$ (temperature, $140{ }^{\circ} \mathrm{C}$, solid-to-liquid ratio, 1:30, pressure, $4 \mathrm{MPa}$, time, $30 \mathrm{~min}$ ) 
Temperature is another important factor affecting the extraction efficiency. As shown in Figure $1 \mathrm{~B}$, the recovery of mogrosides increased up to $70.5 \%$ at $140{ }^{\circ} \mathrm{C}$. However, the recovery of mogrosides decreased to $44.2 \%$ at $170{ }^{\circ} \mathrm{C}$. When the extraction temperature was lower than $140{ }^{\circ} \mathrm{C}$, the effects of the viscosity, surface tension, diffusion, and thermal desorption of subcritical water on the target compounds showed dominant roles on the yield of extraction (Teо et al., 2010; THоO et al., 2010). Over $140^{\circ} \mathrm{C}$, the strong burnt smell of extracts could be due to Maillard reactions and resulted in decreased yields of mogrosides. XIA and co-workers (2008) found that the total recovery of mogrosides decreased from 47.1 to $39.5 \%$ when the temperature elevated from 150 to $180^{\circ} \mathrm{C}$. The recovery of mogroside $\mathrm{V}$ increased from 80 to $110^{\circ} \mathrm{C}$ (up to $16.89 \mathrm{mg} \mathrm{g}^{-1}$, Figure 1B). However, the content of mogroside $\mathrm{V}$ decreased to $12.32 \mathrm{mg} \mathrm{g}^{-1}$ at $140{ }^{\circ} \mathrm{C}$ and almost nothing was detected at $200{ }^{\circ} \mathrm{C}$. The increase of mogroside $\mathrm{V}$ content from 80 to $110^{\circ} \mathrm{C}$ could be due to the positive effect of temperature on extraction (TEO et al., 2010). The decrease of extraction yield of mogroside $\mathrm{V}$ from 110 to $200^{\circ} \mathrm{C}$ might be attributed to its thermal degradation.

The addition of co-solvents could change the physicochemical properties of solvents and improve the extraction efficiency (GAO et al., 2010). Higher amount of glycyrrhizin (a natural sweetener from liquorice) could be obtained by SWE with added ammonia $(0.01 \%$, w/v) (MAMATA \& PALASH, 2008; TeO et al., 2010). As shown in Figure 1C, addition 15\% (v/v) of ethanol in the extraction solvent was preferred with a maximal yield of mogroside $\mathrm{V}$.

\subsection{Effect of SWE parameters on the contents of total phenolics and flavonoids}

Lo-han-kuo extract prepared by SWE in this study contained large amount of phenolics $\left(17 \mathrm{mg} \mathrm{g}^{-1}\right.$ to $\left.43 \mathrm{mg} \mathrm{g}^{-1}\right)$. As shown in Figure $2 \mathrm{~A}$, the recovery of total phenolics increased remarkably from 0 to $10 \mathrm{~min}$, and did not change significantly after $10 \mathrm{~min}$ of extraction $(\mathrm{P}>0.05)$.

The flavonoids from Siraitia grosvenorii include mangosteen flavin, ketone aglycone quercetin, and kaempferol-3,7- $\alpha$-L-rhamnoside (CHEN et al., 2003), and range from 7 to 11 $\mathrm{mg} \mathrm{g}^{-1}$ in this study (Figure 2A). There was an increase of flavonoids during the first $20 \mathrm{~min}$ (up to $11.90 \mathrm{mg} \mathrm{g}^{-1}$ ) and a plateau was reached after $20 \mathrm{~min}$.

The effect of temperature on the contents of total phenolics and total flavonoids is shown in Figure 2B. Both were significantly different $(\mathrm{P}<0.05)$ at different temperatures. With the increase of extraction temperature $\left(80-110{ }^{\circ} \mathrm{C}\right)$, the content of flavonoids increased significantly. At the temperature range of $110-170{ }^{\circ} \mathrm{C}$, the content of flavonoids remained unchanged. When the temperature was increased to $>170{ }^{\circ} \mathrm{C}$, less flavonoids were obtained. At the temperature range of $80-110^{\circ} \mathrm{C}$, mass transfer and dissolution of flavonoids were enhanced (Kiм \& MAZzA, 2006). When the temperature was set between $110-170{ }^{\circ} \mathrm{C}$, the mass transfer was accelerated, and some flavonoids might be degraded as a result of the high temperature trigged reactions. The plateau of flavonoids concentrations might be a balance between the degradation and improved dissolution of flavonoids in subcritical water. When the temperature was over $170{ }^{\circ} \mathrm{C}$, the thermal degradation of flavonoids increased. Kıм and MAzza (2006) reported that the lignin decomposed to free phenols at high temperatures. The content of total phenolics increased when the extraction temperature increased from $80^{\circ} \mathrm{C}$ to $140{ }^{\circ} \mathrm{C}$, and then decreased when the temperature was $>140{ }^{\circ} \mathrm{C}$, which was similar to the report from Ko and co-workers (2011). The reduction and epimerization of flavanols could be the reason (Ko et al., 2014). 

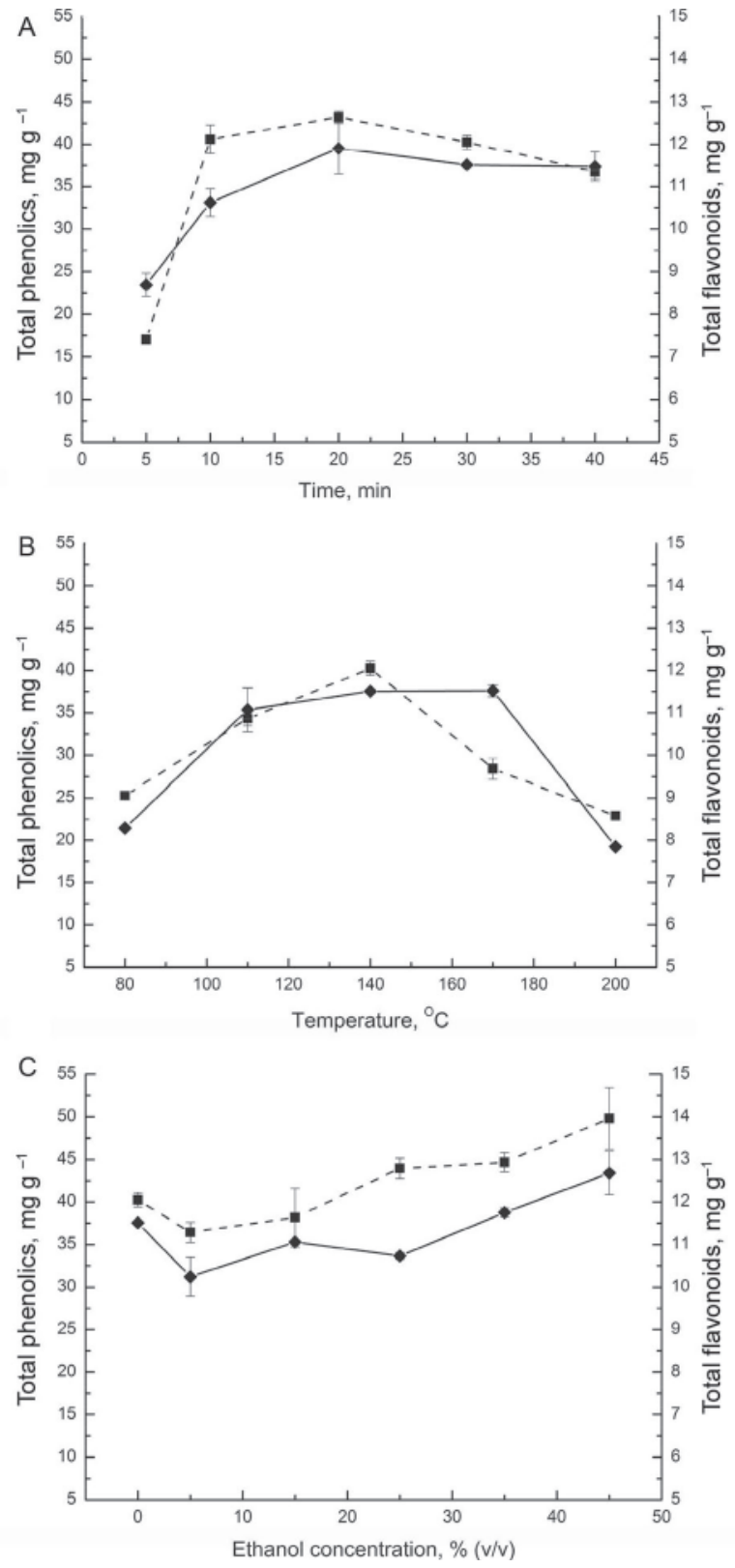

Fig. 2. Effects of subcritical water extraction (SWE) parameters on the contents of total phenolics and total flavonoids (匹: Total phenolics; $\$$ : total flavonoids).

A: The effect of SWE time on the recoveries of mogrosides and mogroside V (temperature, $140{ }^{\circ} \mathrm{C}$, solid-to-liquid ratio, $1: 30$, pressure, $4 \mathrm{MPa}$ );

B: The effect of SWE temperature on the recoveries of mogrosides and mogroside V (solid-to-liquid ratio, 1:30, pressure, $4 \mathrm{MPa}$, time, $30 \mathrm{~min}$ );

$\mathrm{C}$ : The effect of ethanol concentration on the recoveries of mogrosides and mogroside $\mathrm{V}$ (temperature, $140{ }^{\circ} \mathrm{C}$, solid-to-liquid ratio, 1:30, pressure, $4 \mathrm{MPa}$, time, $30 \mathrm{~min}$ ) 
As shown in Figure $2 \mathrm{C}$, there was no significant difference $(\mathrm{P}>0.05)$ among the concentrations of total phenolics and flavonoids with the rise of ethanol concentration. To subcritical water modified with ethanol, the dielectric constant data of solvents decreased with the increase of ethanol concentration, but the decrease was smaller at high temperatures than those at ambient temperature (CURREN \& KING, 2001), and this could be the reason to little changes of total flavonoids concentrations.

\subsection{Antioxidant capacity evaluation of lo-han-kuo extract}

Table 1 shows the antioxidant capacity of lo-han-kuo extract on scavenging DPPH radical. For samples without ethanol addition, the highest antioxidative extract was obtained at $140{ }^{\circ} \mathrm{C}$ for $20 \mathrm{~min}$. When the concentration of ethanol increased from $5 \%$ to $15 \%$, the antioxidant capacity of extract increased from $8.55 \mathrm{mg} \mathrm{g}^{-1}$ to $10.21 \mathrm{mg} \mathrm{g}^{-1}$, and little change $(\mathrm{P}>0.05)$ was observed with more ethanol addition.

Table 1. Antioxidant capacity evaluation of lo-han-kuo extracts by SWE

\begin{tabular}{|c|c|c|c|c|c|}
\hline $\begin{array}{l}\text { Extraction time, } \\
\qquad(\min )\end{array}$ & $\begin{array}{l}\text { Trolox } \\
\text { equivalent } \\
\left(\mathrm{mg} \mathrm{g}^{-1}\right)\end{array}$ & $\begin{array}{c}\text { Extraction } \\
\text { temperature, } \\
\left({ }^{\circ} \mathrm{C}\right)\end{array}$ & $\begin{array}{l}\text { Trolox } \\
\text { equivalent } \\
\left(\mathrm{mg} \mathrm{g}^{-1}\right)\end{array}$ & $\begin{array}{c}\text { Extraction ethanol } \\
\text { concentration } \\
(\%)\end{array}$ & $\begin{array}{c}\text { Trolox } \\
\text { equivalent } \\
\left(\mathrm{mg} \mathrm{g}^{-1}\right)\end{array}$ \\
\hline 5 & $7.560 \pm 0.048^{\mathrm{a}}$ & 80 & $6.477 \pm 0.201^{\mathrm{a}}$ & 5 & $8.552 \pm 0.352^{\mathrm{a}}$ \\
\hline 10 & $8.288 \pm 0.046^{\mathrm{b}}$ & 110 & $7.112 \pm 0.023^{b}$ & 15 & $10.21 \pm 1.034^{\mathrm{a}}$ \\
\hline 20 & $8.481 \pm 0.024^{\mathrm{b}}$ & 140 & $8.116 \pm 0.006^{\mathrm{c}}$ & III & $10.73 \pm 0.250^{\mathrm{b}}$ \\
\hline 30 & $8.117 \pm 0.006^{\mathrm{b}}$ & 170 & $7.765 \pm 0.296^{\mathrm{c}}$ & 35 & $10.96 \pm 0.217^{\mathrm{b}}$ \\
\hline 40 & $8.176 \pm 0.017^{\mathrm{b}}$ & 200 & $6.220 \pm 0.036^{\mathrm{a}}$ & 45 & $10.74 \pm 0.199^{b}$ \\
\hline
\end{tabular}

I: Lo-han-kuo powder was extracted with subcritical water at $140{ }^{\circ} \mathrm{C}$ and $4 \mathrm{MPa}$ with a solid-to-liquid ratio of 1:30; II: Lo-han-kuo powder was extracted with subcritical water at $4 \mathrm{MPa}$ for $30 \mathrm{~min}$ with a solid-to-liquid ratio of 1:30; III: Lo-han-kuo powder was extracted with subcritical water at $140{ }^{\circ} \mathrm{C}, 4 \mathrm{MPa}$ for $30 \mathrm{~min}$ with a solid-to-liquid ratio of 1:30. Values are expressed as means \pm S.D. $(n=3)$; The numbers in each column of each factors (extraction time, extraction temperature, extraction ethanol concentration) marked with different superscript letters were significantly $(\mathrm{P}<0.05)$ different.

The antioxidant capacity might be associated with bioactive compounds. Regression analyses between the antioxidant capacity and the recovery of mogrosides, the contents of mogroside $\mathrm{V}$, total phenolics, and total flavonoids were presented in Figure 3. The higher values of coefficients in fitted equations indicated that the recovery of mogrosides had the greater influence on the antioxidant capacity of lo-han-kuo extract. The lowest linear relationship between the concentration of mogroside $\mathrm{V}$ and the antioxidant activity of lo-hankuo extract could be due to the decomposition of mogroside $\mathrm{V}$ in subcritical water as shown in Fig. 1A and Fig. 1B. 

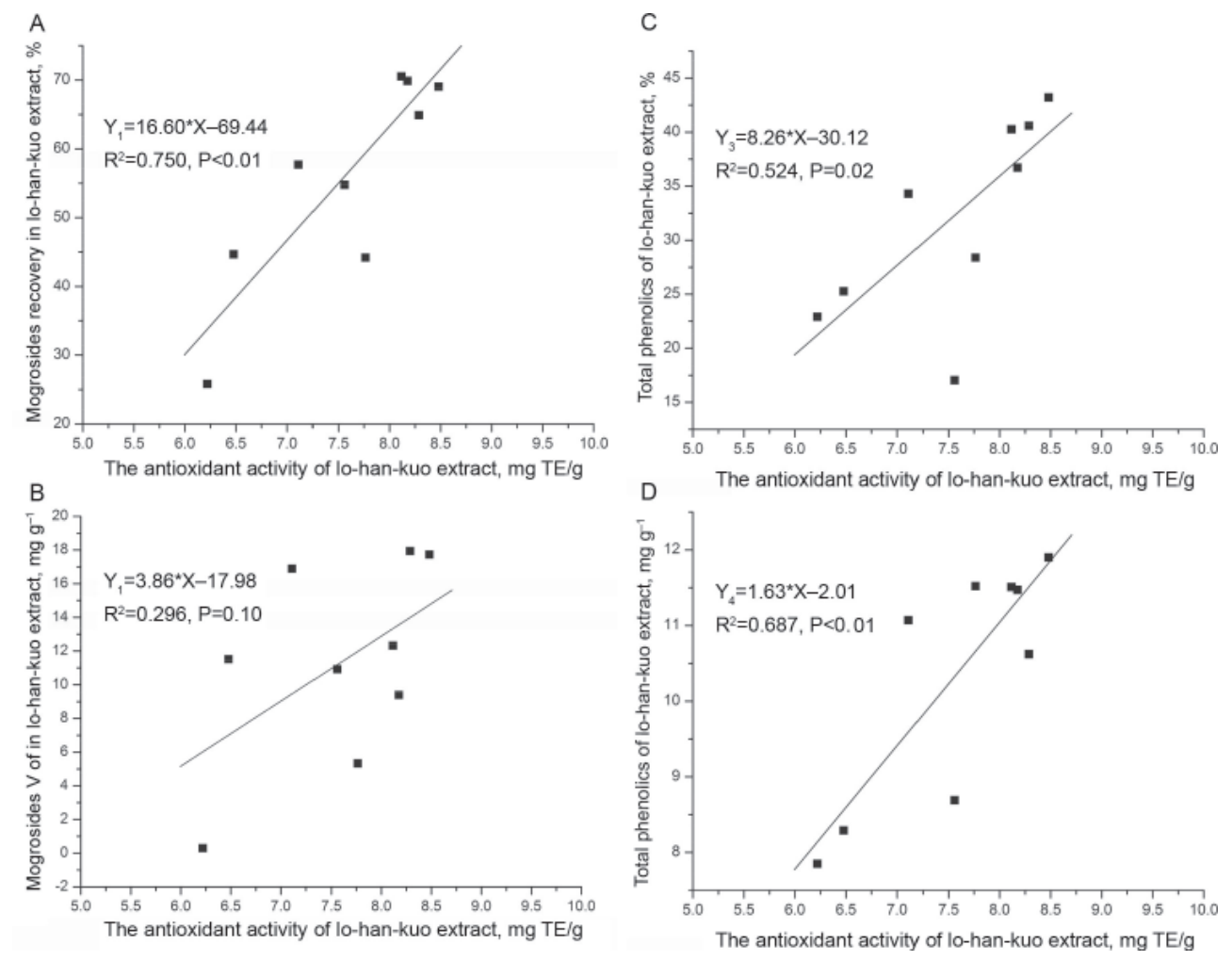

Fig. 3. The relationship between the antioxidant capacity $(\mathrm{X})$ and antioxidant concentration $(\mathrm{Y})$ in lo-han-kuo extracts $\left(\mathrm{Y}_{1}, \mathrm{Y}_{2}, \mathrm{Y}_{3}, \mathrm{Y}_{4}\right.$ are corresponding to the contents of mogrosides recovery, mogroside $\mathrm{V}$, total phenolics, and total flavonoids, respectively).

Table 2. Multiple linear regression statistics of the antioxidant capacity and contents of bioactive components

\begin{tabular}{lccccc}
\hline & \multicolumn{2}{c}{ Unstandardized coefficients } & $\begin{array}{c}\text { Standardized } \\
\text { coefficients }\end{array}$ & t & Sig. \\
\cline { 2 - 5 } & B & Std. Error & Beta & 1.775 & 0.106 \\
\hline Constant & 3.471 & 1.955 & & 3.038 & 0.013 \\
Mogrosides recovery (MR) & 7.301 & 2.403 & 0.835 & -1.236 & 0.245 \\
Mogroside V (MV) & -0.079 & 0.064 & -0.260 & 1.001 & 0.341 \\
Total phenolics (TP) & 0.052 & 0.052 & 0.310 & -0.208 & 0.840 \\
Total flavonoids (TF) & -0.059 & 0.284 & -0.055 & & \\
\hline
\end{tabular}

a: The antioxidant activity of DPPH scavenging capacity was expressed as Trolox equivalent. 


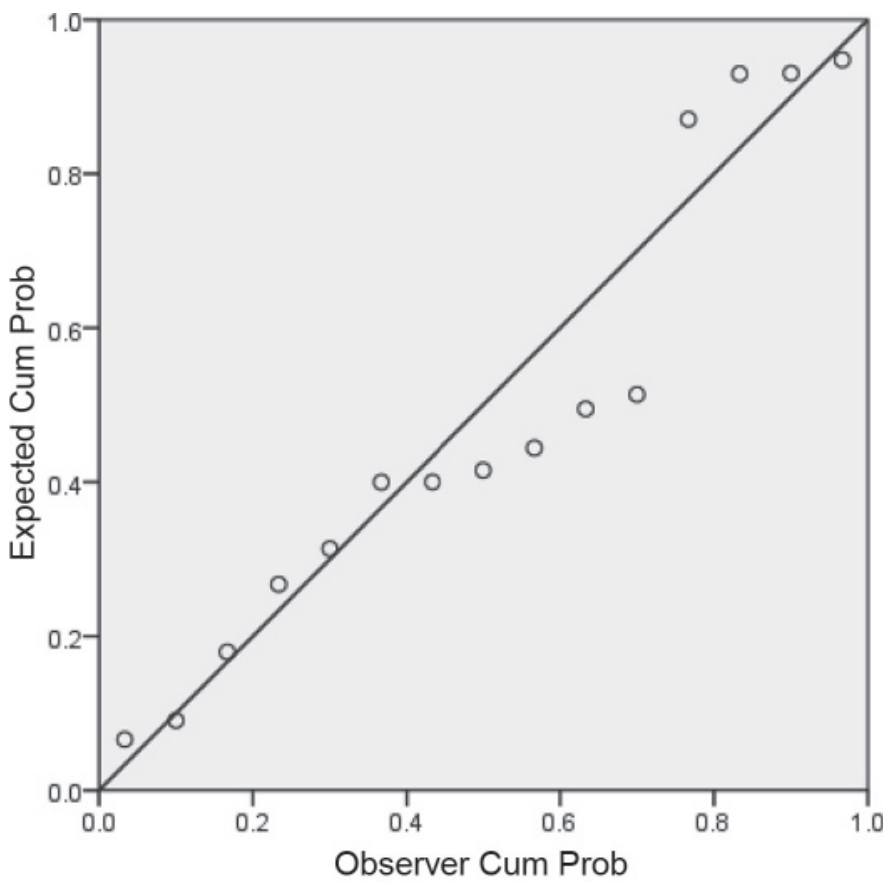

Fig. 4. Probability-probability plot of lo-han-kuo extract DPPH scavenging capacity

Multiple linear regression of DPPH elimination capacity (Y) to mogrosides recovery, mogroside $\mathrm{V}$, total phenolics, and flavonoids was expressed in Table 2 and plotted in Figure 4 , the data were not all closely distributed on or near the comparison line. The reduction or epimerization reaction among constituents in the extracts could alter their distribution (Ko et al., 2014). The DPPH elimination capacity of lo-han-kuo extract was strongly affected by mogrosides recovery $(\mathrm{P}<0.05)$ and was not significantly affected by mogroside $\mathrm{V}$, total phenolics, and flavonoids ( $\mathrm{P}>0.05$ ). The relatively low content of mogroside $\mathrm{V}$ and the main antioxidant of 11-oxo-mogroside $\mathrm{V}$ in lo-han-kuo extracts could be the reason for no significance $(\mathrm{P}>0.05)$ of mogroside $\mathrm{V}$ in regression analysis (TAKEO et al., 2002).

\section{Conclusions}

Subcritical water extraction can be used to extract functional compounds from lo-han-kuo fruit, and the recommended condition is at $140{ }^{\circ} \mathrm{C}$ for $20 \mathrm{~min}$ with $15 \%$ ethanol addition. Statistical analysis results suggest that the antioxidant capacity of lo-han-kuo extract is mainly attributed to mogrosides recovery. 


\section{References}

Chen, Q., YAnG, R. \& YI, X. (2003): RP-HPLC determination of total flavone glycoside from the fresh fruits and saponin of Siraitia grosvenorii. Food Science, 24(5), 133-135. (in Chinese).

Curren, M.S.S. \& King, J.W. (2001): Solubility of triazine pesticides in pure and modified subcritical water. Anal. Chem., 73, 740-745.

GaO, Y., LiU, X., Xu, H., Zhao, J., WANG, Q., LiU, G. \& HAO, Q. (2010): Optimization of supercritical carbon dioxide extraction of lutein esters from marigold (Tagetes erecta L.) with vegetable oils as continuous co-solvents. Sep. Purif. Technol., 71, 214-219.

KiM, J.W. \& MAzzA, G. (2006): Optimization of extraction of phenolic compounds from flax shives by pressurized low-polarity water. J. Agr. Food Chem., 54, 7575-7584.

Ko, M.J., Cheigh, C.I. \& Chо, S.W. (2011): Subcritical water extraction of flavonol quercetin from onion skin. J. Food Eng., 102, 327-333.

Ko, M.J., Cheigh, C.I. \& Chung, M.S. (2014): Optimization of subcritical water extraction of flavonols from green tea leaves. J. Agr. Food Chem., 62, 6828-6833.

Lu, F., Liu, J., Huang, Y. \& Li, D. (2008): Simultaneous determination of six cucurbitane triterpene glycosides in Siraitia grosvenorii fruit using high performance liquid chromatography. Chinese J. Chromatogr., 26, 504508. (in Chinese)

Mamata, M. \& Palash, P. (2008): A novel process for extraction of natural sweetener from licorice (Glycyrrhiza glabra) roots. Sep. Purif. Technol., 63, 539-545.

PAN, M.H., YANG, J.R. \& Tsai, M.L. (2009): Anti-inflammatory effect of Momordica grosvenori Swingle extract through suppressed LPS-induced upregulation of iNOS and COX-2 in murine macrophages. J. Funct. Foods, $1,145-152$.

Qi, X., Chen, W., Zhang, L. \& XIE, B. (2008): Mogrosides extract from Siraitia grosvenorii scavenges free radicals in vitro and lowers oxidative stress, serum glucose, and lipid levels in alloxan induced diabetic mice. Nutr. Res., 28, 278-284.

Takasaki, M., Konoshima, T., Murata, Y., Sugiura, M., Nishino, H., Tokuda, H., Matsumoto, K., Kasai, R. \& YAMASAKI, K. (2003): Anticarcinogenic activity of natural sweeteners, cucurbitane glycosides, from Momordica grosvenori. Cancer Lett., 198, 37-42.

Takeo, E., Yoshida, H., Tada, N., Shingu, T., Matsuura, H., Murata, Y., Yoshikawa, S., Ishikawa, T., Nakamura, H., Ohsuzu, F. \& Kohda, H. (2002): Sweet elements of Siraitia grosvenorii inhibit oxidative modification of low-density lipoprotein. J. Atheroscler. Thromb., 9, 114-120.

Teo, C.C., Tan, S.N., Yong, J.W.H., Hew, C.S. \& Ong, E.S. (2010): Pressurized hot water extraction (PHWE). J. Chromatogr. A, 1217, 2484-2494.

Thoo, Y.Y., Ho, S.K., Liang, J.Y., Ho, C.W. \& Tan, C.P. (2010): Effects of binary solvent extraction system, extraction time and extraction temperature on phenolic antioxidants and antioxidant capacity from mengkudu (Morinda citrifolia). Food Chem., 120, 290-295.

Xia, Y., Rivero-Huguet, M.E, Hughes, B.H. \& Marshall, W.D. (2008): Isolation of the sweet components from Siraitia grosvenorii. Food Chem., 107, 1022-1028.

Xu, H., Wang, W., Jiang, J., Yuan, F. \& GaO, Y. (2015): Subcritical water extraction and antioxidant activity evaluation with on-line HPLC-ABTS assay of phenolic compounds from marigold (Tagetes erecta L.) flower residues. J. Food Sci. Tech., 52, 3803-3811.

Xu, H., Xu, X., TAO, Y., YuAn, F. \& GaO, Y. (2015): Optimization by response surface methodology of supercritical carbon dioxide extraction of flavour compounds from Chinese liquor vinasse. Flavour Frag. J., 30, $275-281$.

Zhang, L., Qı, X., Chen, W. \& Song, Y. (2006): Study on in vitro antioxidant activity of extracts from Siraitia grosvenorii fruits. Food Science. 27(1), 213-216. (in Chinese). 